\title{
PENERAPAN REGRESI PROBIT BIVARIAT UNTUK MENDUGA FAKTOR-FAKTOR YANG MEMENGARUHI KELULUSAN MAHASISWA (Studi Kasus: Mahasiswa Fakultas MIPA Unversitas Udayana)
}

\author{
Ni Gusti Ketut Trisna Pradnyantari ${ }^{\circledR 1}$, I Komang Gde Sukarsa ${ }^{2}$, Ni Luh Putu Suciptawati ${ }^{3}$ \\ ${ }^{1}$ Jurusan Matematika, Fakultas MIPA - Universitas Udayana [Email: trisnapradnya @gmail.com] \\ ${ }^{2}$ Jurusan Matematika, Fakultas MIPA - Universitas Udayana [Email: sukarsakomang @yahoo.com] \\ ${ }^{3}$ Jurusan Matematika, Fakultas MIPA - Universitas Udayana [Email: putusuciptawati@yahoo.co.id] \\ ${ }^{\S}$ Corresponding Author
}

\begin{abstract}
The aim of this research to estimate the factors that affect students graduation using bivariate probit regression. Bivariate probit regression is a statistical method that involves two response variables which are qualitative and the independent variables are qualitative, quantitative, or a combination of both. In bivariate probit regression model, the result obtained is the probability of the response variable. The result of this research are the factors that affect significantly for students graduation based on study period are majors, sex, and duration of the thesis, while the factors that significantly for students graduation based on GPA are the entry system, duration of the thesis and the number of parents' dependents.
\end{abstract}

Keywords: Bivariate Probit Regression, Study Period, Grade Point Average (GPA), Students Graduation

\section{PENDAHULUAN}

Analisis regresi probit merupakan suatu analisis regresi yang digunakan untuk menganalisis variabel respon yang bersifat kualitatif, dan variabel bebas yang bersifat kualitatif, kuantitatif, atau gabungan dari keduanya. Regresi probit dalam analisisnya menggunakan fungsi distribusi kumulatif dari distribusi normal (Gujarati [1]). Penerapan regresi probit telah dilakukan pada berbagai bidang, seperti pada bidang biostatistika, kesehatan, dan sosial politik. Umumnya analisis regresi probit yang diterapkan hanya menggunakan satu variabel respon. Pada kasus tertentu terdapat penelitian yang memerlukan dua variabel respon, sehingga diperlukan analisis yang dapat menyelesaikan permasalahan tersebut. Salah satu analisis yang dapat digunakan adalah analisis regresi probit bivariat. Permasalahan yang dapat dianalisis menggunakan regresi probit bivariat adalah permasalahan tentang kelulusan mahasiswa.

Kelulusan mahasiswa merupakan hasil yang diperoleh mahasiswa dari proses belajarnya. Pada kenyataannya tidak semua mahasiswa lulus tepat waktu atau sesuai dengan waktu yang ditetapkan oleh tempat mahasiswa tersebut menepuh pendidikannya. Keberhasilan mahasiswa dalam menempuh studinya selain dapat dilihat dari waktu yang ditempuh, dapat juga diukur dari predikat kelulusan yang diperoleh. Predikat kelulusan dibagi menjadi tiga yaitu memuaskan, sangat memuaskan, dan dengan pujian. Predikat kelulusan ditetapkan berdasarkan pada lama studi yang ditempuh dan nilai Indeks Prestasi Kumulatif (IPK) mahasiswa. Oleh karena itu, dalam menentukan kelulusan mahasiswa terdapat dua hal yang perlu diperhatikan yaitu berdasarkan lama studi 
yang ditempuh mahasiswa dan nilai IPK yang diperoleh.

Pada Fakultas MIPA Universitas Udayana, tidak semua mahasiswa di setiap jurusannya memenuhi persyaratan yang telah ditetapkan yakni lulus dalam waktu kurang atau sama dengan empat tahun. Untuk mengetahui penyebab kelulusan mahasiswa Fakultas MIPA Universitas Udayana banyak yang tidak tepat waktu dan tetap memperhitungkan nilai IPK yang diperoleh mahasiswa diperlukan suatu analisis yang dapat menyelesaikan permasalahan tersebut. Pada penelitian ini dilakukan analisis faktor-faktor yang memengaruhi kelulusan mahasiswa Fakultas MIPA Universitas Udayana dengan regresi probit bivariat.

Model regresi probit bivariat merupakan model yang dikembangkan dari model regresi probit (Greene [2]). Pada analisisnya regresi probit bivariat melibatkan dua variabel respon yang bersifat kualitatif dan variabel bebasnya dapat berupa data kuantitatif, data kualitatif atau gabungan dari keduanya dan mengandaikan galatnya berdistribusi normal bivariat (Yong [3]). Menurut Kapur dan Saxena [4] distribusi normal bivariat merupakan bentuk pengembangan dari distribusi normal univariat.

Persamaan umum dari model regresi probit bivariat dapat ditulis sebagai berikut:

$$
\begin{aligned}
& Y_{i 1}^{*}=\boldsymbol{\beta}_{i 1}^{\prime} \boldsymbol{X}_{i 1}+\varepsilon_{i 1} \quad, i=1,2, \ldots, n \\
& \text { dengan } \\
& \mathrm{Y}_{\mathrm{i} 1}^{*}= \begin{cases}1, & \mathrm{Y}_{\mathrm{i} 1}^{*}>0 \\
0, & \text { untuk yang lain }\end{cases} \\
& Y_{i 2}^{*}=\boldsymbol{\beta}_{i 2}^{\prime} \boldsymbol{X}_{i 2}+\varepsilon_{i 2} \quad, i=1,2, \ldots, n \\
& \text { dengan } \\
& \mathrm{Y}_{\mathrm{i} 2}^{*}= \begin{cases}1, & \mathrm{Y}_{\mathrm{i} 2}^{*}>0 \\
0, & \text { untuk yang lain }\end{cases}
\end{aligned}
$$

dengan $Y_{i 1}^{*}$ dan $Y_{i 2}^{*}$ menyatakan variabel respon yang berukuran $n \times 1$. $\boldsymbol{\beta}_{i 1}^{\prime}$ dan $\boldsymbol{\beta}_{i 2}^{\prime}$ menyatakan vektor koefisien dari variabel bebas yang berukuran $p \times 1 . \quad \boldsymbol{X}_{i 1}$ dan $\boldsymbol{X}_{i 2}$ menyatakan vektor variabel bebas.

Pendugaan parameter regresi probit bivariat menggunakan metode Maximum Likelihood Estimation. Dalam pengujian parameter model probit bivariat dilakukan uji secara serentak dan parsial. Pengujian secara serentak model probit bivariat sebagai berikut:

1. Perumusan Hipotesis

$H_{0}: \beta_{j 1}=\cdots=\beta_{j p}=0$, untuk $j=1,2$

$H_{1}$ : paling sedikit terdapat satu $\beta_{j k} \neq 0$, untuk $j=1,2$ dan $k=1,2, \ldots, p$.

2. Statistik Uji

$\chi_{\text {hitung }}^{2}=-2 \log \left(\frac{\text { likelihood tanpa variabel bebas }}{\text { likelihood dengan variabel bebas }}\right)$

\section{Kriteria Pengujian}

dengan mengambil taraf signifikansi $\alpha$, maka $H_{0}$ ditolak jika $p$-value $<\alpha$.

Pengujian secara parsial model probit bivariat sebagai berikut:

1. Perumusan Hipotesis

$H_{0}: \beta_{j k}=0$, untuk $k=0,1, \ldots, p$ (tidak ada pengaruh signifikan variabel bebas yang diuji terhadap variabel respon)

$H_{1}: \beta_{j k} \neq 0$, untuk $k=0,1, \ldots, p \quad$ (ada pengaruh signifikan variabel bebas yang diuji terhadap variabel respon)

2. Statistik Uji

$$
Z_{j k}=\frac{\hat{\beta}_{j k}}{S E\left(\hat{\beta}_{j k}\right)}
$$

\section{Kriteria Pengujian}

Dengan mengambil taraf signifikansi $\alpha$, maka $H_{0}$ ditolak jika $\left|Z_{j k}\right|>Z_{\alpha / 2}$ atau nilai $p$-value $<\alpha$.

Menentukan model terbaik diperlukan kriteria dalam pemilihannya, salah satu kriteria yang dapat digunakan dalam menentukan model terbaik adalah AIC. AIC merupakan kriteria pemilihan model yang mempertimbangkan banyak parameter dalam model. AIC bertujuan untuk mendapatkan faktor-faktor yang berpengaruh terhadap model. Semakin kecil nilai AIC maka model akan semakin baik. AIC dapat dirumuskan sebagai berikut (Agresti [1]):

AIC $=-2$ (maksimum log likelihood - jumlah parameter dalam model) 


\section{METODE PENELITIAN}

Data yang digunakan dalam penelitian ini adalah data sekunder yaitu data lulusan mahasiswa Fakultas MIPA Universitas Udayana periode 2009-2014 sebanyak 906 sampel. Adapun variabel yang digunakan dalam penelitian ini sebagai berikut:

1. Variabel respon $(Y)$ yaitu masa studi $\left(Y_{1}\right)$ dan Indeks Prestasi Kumulatif $\left(Y_{2}\right)$.

2. Variabel bebas $(X)$ yaitu jurusan $\left(X_{1}\right)$, jenis kelamin $\left(X_{2}\right)$, asal SMA $\left(X_{3}\right)$, jalur masuk mahasiswa $\left(X_{4}\right)$, lama skripsi $\left(X_{5}\right)$, pekerjaan ayah $\left(X_{6}\right)$, pekerjaan ibu $\left(X_{7}\right)$, pendidikan ayah $\left(X_{8}\right)$, pendidikan ibu $\left(X_{9}\right)$, jumlah tanggungan orangtua $\left(X_{10}\right)$.

Langkah-langkah analisis pemodelan probit bivariat antara lain: Mengumpulkan dan menyeleksi data; Melakukan analisis statistik deskriptif terhadap semua variabel yang terdapat dalam penelitian; Melakukan analisis model regresi probit bivariate; Melakukan pengujian parameter secara simultan model regresi probit bivariate; Melakukan pengujian parameter secara parsial model regresi probit bivariate; Menghitung nilai AIC; dan Interpretasi model terbaik.

\section{HASIL DAN PEMBAHASAN}

Pada penelitian ini dianalisis faktor-faktor yang memengaruhi kelulusan mahasiswa Fakultas MIPA Universitas Udayana dengan menggunakan metode regresi probit bivariat. Variabel masa studi yang digunakan dalam penelitian ini dibagi menjadi dua kategori yaitu masa studi tepat waktu dan masa studi tidak tepat waktu, sedangkan untuk variabel IPK dibagi menjadi dua kategori yaitu nilai IPK $\leq 3$ dan nilai IPK $>3$.

Jumlah mahasiswa dengan masa studi tidak tepat waktu sebanyak 509 orang dan masa studi tepat waktu sebanyak 397 orang. Persentase masa studi mahasiswa Fakultas MIPA Universitas Udayana yang tidak tepat waktu sebesar $56,2 \%$ dan masa studi mahasiswa Fakultas MIPA Universitas Udayana yang tepat waktu sebesar 43,8\%. Dapat disimpulkan bahwa mahasiswa yang lulus tidak tepat waktu lebih banyak daripada mahasiswa yang lulus tepat waktu. Hal ini berarti kelulusan dengan masa studi tidak tepat waktu di fakultas MIPA Universitas Udayana tinggi sehingga perlu diperbaiki faktor-faktor yang memengaruhi masa studi. Jumlah mahasiswa yang memiliki IPK $\leq 3$ sebanyak 223 orang dan IPK >3 sebanyak 638 orang. Persentase mahasiswa Fakultas MIPA Universitas Udayana yang lulus dan memiliki IPK $\leq 3$ sebesar 24,6\% dan mahasiswa Fakultas MIPA Universitas Udayana yang lulus dan memiliki IPK $>3$ sebesar $75,4 \%$. Ini menunjukkan bahwa mahasiswa yang memiliki IPK $>3$ lebih banyak daripada mahasiswa yang memiliki IPK $\leq 3$.

Pada model regresi probit bivariat dilakukan pengujian secara serentak dan parsial. Pertama, dilakukan pengujian secara serentak dengan hipotesis yang digunakan adalah sebagai berikut:

$H_{0}: \beta_{j 1}=\cdots=\beta_{j p}=0$, untuk $j=1,2$

$H_{1}$ : paling sedikit terdapat satu $\beta_{j k} \neq 0$, untuk $j=1,2$ dan $k=1,2, \ldots, p$

dengan mengambil taraf signifikansi $\alpha$ sebesar 0,05 maka $H_{0}$ ditolak jika $p$-value $<\alpha$. Luaran uji signifikansi variabel bebas secara serentak probit bivariat didapatkan $p$-value $=0,000$, hal ini berarti p-value $<(\alpha=0,05)$. Ini menandakan bahwa hipotesis $H_{0}$ ditolak yang berarti paling sedikit terdapat satu variabel bebas yang berpengaruh signifikan terhadap kelulusan mahasiswa.

Selanjutnya, pada pengujian secara parsial hipotesis yang digunakan dapat ditulis sebagai berikut:

$H_{0}: \beta_{j k}=0$, untuk $k=0,1, \ldots, p$ (tidak ada pengaruh signifikan variabel bebas yang diuji terhadap variabel respon)

$H_{1}: \beta_{j k} \neq 0, \quad$ untuk $\quad k=0,1, \ldots, p \quad($ ada pengaruh signifikan variabel bebas yang diuji terhadap variabel respon)

dengan mengambil taraf signifikansi $\alpha$, maka $H_{0}$ ditolak jika $p$-value $<\alpha$. Luaran uji signifikansi variabel bebas secara parsial probit bivariat dapat dilihat pada Tabel 1 . 
Tabel 1. Penduga Parameter Probit Bivariat (Masa Studi)

\begin{tabular}{|l|l|l|}
\hline Variabel Bebas & Penduga & $\mathrm{p}$-value \\
\hline Konstanta & $-1,127524$ & 0,001 \\
\hline Jurusan $\left(X_{1}\right)$ & 0,1458026 & 0,000 \\
\hline Jenis Kelamin $\left(X_{2}\right)$ & 0,3479638 & 0,000 \\
\hline Asal SMA $\left(X_{3}\right)$ & $-0,0877332$ & 0,372 \\
\hline Jalur Masuk $\left(X_{4}\right)$ & 0,150442 & 0,098 \\
\hline Lama Skripsi $\left(X_{5}\right)$ & $-0,0351231$ & 0,005 \\
\hline Pekerjaan Ayah $\left(X_{6}\right)$ & $-0,0319356$ & 0,410 \\
\hline Pekerjaan Ibu $\left(X_{7}\right)$ & $-0,0122442$ & 0,639 \\
\hline Pendidikan Ayah $\left(X_{8}\right)$ & 0,0562298 & 0,154 \\
\hline Pendidikan Ibu $\left(X_{9}\right)$ & $-0,018891$ & 0,589 \\
\hline $\begin{array}{l}\text { Jumlah Tanggungan } \\
\text { Orangtua }\left(X_{10}\right)\end{array}$ & $-0,018957$ & 0,589 \\
\hline
\end{tabular}

dengan mengambil tingkat signifikansi $\alpha$ sebesar 0,05 pada Tabel 1 terdapat beberapa variabel bebas yang menunjukkan nilai $p$-value lebih kecil dari nilai $\alpha$, sehingga dapat disimpulkan tolak $\mathrm{H}_{0}$ yang artinya ada pengaruh signifikan variabel bebas yang diuji terhadap variabel respon. Terdapat tiga variabel bebas yang berpengaruh secara signifikan atau $p$-value $<(\alpha=0,05)$ terhadap masa studi yang ditempuh mahasiswa di Fakultas MIPA Universitas Udayana. Variabel bebas yang berpengaruh signifikan tersebut adalah variabel jurusan $\left(X_{1}\right)$, jenis kelamin $\left(X_{2}\right)$, dan lama skripsi $\left(X_{5}\right)$.

Tabel 2. Pendugaan Parameter Probit Bivariat (IPK)

\begin{tabular}{|l|l|l|}
\hline Variabel Bebas & Penduga & $\mathrm{p}$-value \\
\hline Konstanta & 1,839987 & 0,000 \\
\hline Jurusan $\left(X_{1}\right)$ & $-0,0270586$ & 0,412 \\
\hline Jenis Kelamin $\left(X_{2}\right)$ & 0,0908259 & 0,344 \\
\hline Asal SMA $\left(X_{3}\right)$ & $-0,1585889$ & 0,127 \\
\hline Jalur Masuk $\left(X_{4}\right)$ & $-0,3901231$ & 0,000 \\
\hline Lama Skripsi $\left(X_{5}\right)$ & $-0,0502496$ & 0,000 \\
\hline Pekerjaan Ayah $\left(X_{6}\right)$ & $-0,0317883$ & 0,457 \\
\hline Pekerjaan Ibu $\left(X_{7}\right)$ & 0,0159588 & 0,580 \\
\hline Pendidikan Ayah $\left(X_{8}\right)$ & 0,0781178 & 0,071 \\
\hline Pendidikan Ibu $\left(X_{9}\right)$ & $-0,0175426$ & 0,655 \\
\hline $\begin{array}{l}\text { Jumlah Tanggungan } \\
\text { Orangtua }\left(X_{10}\right)\end{array}$ & $-0,0749863$ & 0,049 \\
\hline
\end{tabular}

Tabel 2 menunjukkan pendugaan parameter probit bivariat berdasarkan IPK secara parsial. Dengan mengambil taraf signifikansi $\alpha$ sebesar 0,05 pada Tabel 2 terdapat beberapa variabel bebas yang menunjukkan p-value yang diperoleh lebih keci dari $\alpha$. Ini menandakan bahwa tolak $\mathrm{H}_{0}$ yang berarti ada pengaruh signifikan variabel bebas yang diuji terhadap variabel respon.Variabel bebas yang berpengaruh secara signifikan atau $p$-value $<$ ( $=0,05)$ terhadap IPK mahasiswa di Fakultas MIPA Universitas Udayana adalah variabel jalur masuk $\left(X_{4}\right)$, lama skripsi $\left(X_{5}\right)$, dan jumlah tanggungan orang tua $\left(X_{10}\right)$. Selanjutnya mencari model terbaik dari kelulusan mahasiswa dengan menggunakan regresi probit bivariat.

Berdasarkan data lulusan Fakultas MIPA Universitas Udayana yang terdiri dari 10 variabel bebas, jumlah model regresi probit bivariat yang terbentuk adalah 1023 model. Pemilihan model terbaik dilakukan dengan memperhitungkan nilai AIC terkecil. Nilai AIC terkecil yaitu sebesar 2116 yang memuat variabel jurusan $\left(X_{1}\right)$, jenis kelamin $\left(X_{2}\right)$, jalur masuk $\left(X_{4}\right)$, lama skripsi $\left(X_{5}\right)$ dan jumlah tanggungan orangtua $\left(X_{10}\right)$. Pengujian parameter model terbaik regresi probit bivariat dapat dilihat pada tabel berikut:

Tabel 3. Hasil Pendugaan dan Pengujian Parameter Model Terbaik (Masa Studi)

\begin{tabular}{|l|l|l|}
\hline Variabel bebas & Penduga & $\mathrm{p}$-value \\
\hline Konstanta & $-1,26205$ & 0,000 \\
\hline Jurusan $\left(X_{1}\right)$ & 0,1440816 & 0,000 \\
\hline Jenis Kelamin $\left(X_{2}\right)$ & 0,3501033 & 0,000 \\
\hline Jalur Masuk $\left(X_{4}\right)$ & 0,148055 & 0,100 \\
\hline Lama Skripsi $\left(X_{5}\right)$ & $-0,0364149$ & 0,003 \\
\hline $\begin{array}{l}\text { Jumlah Tanggungan } \\
\text { Orangtua }\left(X_{10}\right)\end{array}$ & $-0,022146$ & 0,534 \\
\hline
\end{tabular}

pada Tabel 3 didapatkan model terbaik probit bivariat dari masa studi sebagai berikut:

$$
\begin{aligned}
Y_{1}^{*}= & -1,26205+0,1440816 X_{1} \\
& +0,3501033 X_{2}-0,0364149 X_{5}
\end{aligned}
$$

berdasarkan model regresi probit bivariat yang diperoleh maka didapat faktor-faktor yang berpengaruh terhadap kelulusan mahasiswa berdasarkan masa studi adalah jurusan, jenis kelamin dan lama skripsi serta nilai prediksi probabilitas mahasiswa Fakultas MIPA Universitas Udayana yang lulus dengan masa studi tepat waktu. Sebagai contoh akan dihitung probabilitas mahasiswa yang lulus dengan masa studi tepat waktu adalah mahasiswa dari jurusan kimia, berjenis kelamin laki-laki dan lama 
pengerjaan skripsi selama dua bulan. Dengan menggunakan tabel $\mathrm{z}$ probabilitas mahasiswa yang lulus dengan masa studi tepat waktu sebesar $20,04 \%$.

Tabel 4. Hasil Pendugaan dan Pengujian Parameter Model Terbaik (IPK)

\begin{tabular}{|l|l|l|}
\hline Variabel bebas & Penduga & p-value \\
\hline Konstanta & 1,81512 & 0,000 \\
\hline Jurusan $\left(X_{1}\right)$ & $-0,0299241$ & 0,361 \\
\hline Jenis Kelamin $\left(X_{2}\right)$ & 0,0986721 & 0,302 \\
\hline Jalur Masuk $\left(X_{4}\right)$ & $-0,3955463$ & 0,000 \\
\hline Lama Skripsi $\left(X_{5}\right)$ & $-0,0521588$ & 0,000 \\
\hline $\begin{array}{l}\text { Jumlah Tanggungan } \\
\text { Orangtua }\left(X_{10}\right)\end{array}$ & $-0,077843$ & 0,039 \\
\hline
\end{tabular}

berdasarkan Tabel 4 maka diperoleh model terbaik probit bivariat dari IPK sebagai berikut:

$Y_{2}^{*}=1,81512-0,3955463 X_{4}$

$$
-0,0521588 X_{5}-0,077843 X_{10}
$$

pada model regresi probit bivariat yang diperoleh maka didapat faktor-faktor yang berpengaruh terhadap kelulusan mahaiswa berdasarkan IPK adalah jalur masuk, lama skripsi dan jumlah tanggungan orang tua serta nilai prediksi probabilitas mahasiswa Fakultas MIPA Universitas Udayana yang lulus dengan IPK $>3$. Sebagai contoh akan dihitung probabilitas mahasiswa yang lulus dengan IPK $>3$ adalah mahasiswa dengan jalur masuk PMDK, lama pengerjaan skripsi selama dua bulan dan jumlah anak yang ditanggung orangtua sebanyak satu orang. Dengan menggunakan tabel $\mathrm{z}$ diperoleh probabilitas mahasiswa yang lulus dengan IPK $>3$ sebesar $10,74 \%$.

\section{KESIMPULAN}

Berdasarkan hasil dan pembahasan yang telah dilakukan sebelumnya maka dapat ditarik kesimpulan sebagai berikut: faktor-faktor yang memengaruhi kelulusan mahasiswa berdasarkan masa studi adalah jurusan, jenis kelamin dan lama skripsi, sedangkan faktor-faktor yang memengaruhi kelulusan mahasiswa berdasarkan IPK adalah jalur masuk, lama skripsi dan jumlah tanggungan orang tua.

\section{DAFTAR PUSTAKA}

[1] Gujarati, D.N. 2004. Basic Econometrics. 4th ed. The McGraw-Hill: New York.

[2] Greene, W.H. 2002. Econometric Analysis. 5th ed. Prentice Hall: New Jersey.

[3] Yong, B. 2003. Penaksir Maksimum Likelihood Bagi Model Probit dan Model Probit Bivariat. INTEGRAL, VIII No. 1, pp.11-18.

[4] Kapur, J.N. \& Saxena, H.C. 2007. Mathematical Statistics. 1st ed. S. Chand \& Company Ltd: India

[5] Agresti, A. 2002. Categorical Data Analysis. 2nd ed. A John Wiley \& Sons. Inc: New York. 